\title{
KAMUS ILMU BIOLOGI BERBASIS ANDROID
}

\author{
Mochammad Ichsan ${ }^{1}$ dan Norhayati ${ }^{2}$ \\ Sekolah Tinggi Manajemen Informatika dan Komputer (STMIK) \\ Palangka Raya \\ Jl. G.Obos No.114, Palangka Raya 73112 Indonesia \\ E-mail: salafi ichsan@yahoo.com ${ }^{1)}$, inoynorhayati@gmail.com²)
}

\begin{abstract}
The need for education-themed applications, especially Biology subject that have the term Latin elusive and remembered by the public, especially the students who are studying Natural Sciences (IPA) in addition to the price of a dictionary of biology are relatively expensive complicate the students to buy. By the need of a dictionary and the use of communication devices such as smartphones based on android makes writers interested in creating a dictionary of biology-based android. This application is expected to provide ease in finding biological science terms by categories easily and less cost. Methods that are used in this study include data collection methods (interviews, literature methods, methods of documentation, the experimental method) and the method of system development.In this study, has successfully implemented a dictionary application android based biological term. The programming language PHP and the database used structured based Query Language (SQL) MySQL with kamus.sql name with three (3) tables. The writers applied the waterfall method of software development.
\end{abstract}

Keywords: Android, Biological Sciences, Dictionary

\section{PENDAHULUAN}

\section{Latar Belakang}

Perkembangan Kebutuhan layanan teknologi berbasis teknologi informasi sangat beragam. Selama ini para pengguna telepon seluler dengan sistem operasi android terus melakukan pencarian aplikasi yang terbaru dan pastinya yang paling banyak digunakan. Kebutuhan aplikasi Android bertemakan pendidikan juga banyak dibutuhkan dewasa ini. Salah satu aplikasi yang banyak ditawarkan pada sistem operasi android adalah aplikasi yang bertemakan pendidikan namun masih belum banyak yang membuat aplikasi tentang daftar istilah biasanya hanya bertemakan pengenalan huruf dan angka.

Kebutuhan akan aplikasi yang bertemakan pendidikan terutama Biologi yang memiliki istilah bahasa latin yang sulit dipahami dan diingat oleh masyarakat terutama para siswa yang belajar Ilmu Pengetahuan Alam (IPA) 
selain itu harga kamus biologi yang tergolong mahal menyulitkan siswa untuk membeli. Dengan kebutuhan kamus dan penggunaan perangkat komunikasi seperti smartphone yang berbasis android membuat penulis tertarik membuat kamus ilmu biologi berbasis android.

\section{Kajian Teori}

1. Kamus

Menurut Perpustakan Nasional RI dalam Ensiklopedia Kebahasaan Indonesia (2009:566), kamus berasal dari bahasa Inggris dictionary, merupakan buku referensi yang memuat daftar kata yang disusun menurut urutan abjad dengan keterangan mengenai berbagai segi maknanya dan penggunaannya dalam bahasa.

Selain menjelaskan maksud katakata, biasanya kamus juga memiliki panduan referensi. Untuk memperkuat pemahaman terkadang ada juga ilustrasi didalam kamus.

\section{Ilmu Biologi}

Menurut Nugroho (2003), Biologi merupakan ilmu pengetahuan (science) yang mempelajari tentang perihal kehidupan sejak beberapa juta tahun yang lalu hingga sekarang dengan segala perwujudan dan kompleksitasnya, dimulai dari subpartikel atom hingga interaksi antarmakhluk hidup dan makhluk hidup dengan lingkungannya.

Biologi berasal dari bahasa Yunani bios yang berarti "hidup, kehidupan" dan logos yang berarti "ilmu". Jadi, secara harfiah biologi adalah ilmu tentang kehidupan. Namun, biologi tidak hanya sekedar mempelajari proses kehidupan dan apa yang membuat suatu makhluk hidup dapat hidup. Biologi juga mempelajari tentang habitat makhluk hidup sampai hubungan antara makhluk hidup satu dengan makhluk hidup lain. Biologi juga berkaitan erat dengan beberapa ilmu lain, terutama kimia.

\section{Android}

Menurut Safaat (2011:1), Android adalah sebuah sistem operasi untuk perangkat mobile berbasis linux yang mencakup sistem operasi, middleware, dan aplikasi. Android menyediakan flatform terbuka bagi para pengembang untuk menciptakan aplikasi mereka. Awalnya, Google Inc. membeli Android Inc. yang merupakan pendatang baru yang membuat piranti perangkat lunak untuk ponsel/ smartphone. Kemudian untuk mengembangkan Android 
dibentuklah Open Handset Alliance, konsorsium dari 34 perusahaan piranti keras, piranti lunak, dan telekomunikasi, termasuk Google, HTC, Intel, Motorola, Qualcomm, T-Mobile, dan Nvidia.

\section{PHP (Hypertext Preprocessor)}

Menurut Aditya N.A (2011:1) PHP (Hypertext Preprocessor) adalah bahasa skrip yang dapat ditanamkan atau disisipkan ke dalam HTML. PHP banyak dipakai untuk memprogram situs Web dinamis. PHP dapat digunakan untuk membangun sebuah CMS.

Salah satu kelebihan dari PHP adalah Sifatnya Open Source, maka perubahan dan perkembangan Interpreter pada PHP lebih cepat dan mudah.

5. HTML (Hyper Text Markup Language)

Menurut Arief (2011:23), HTML atau Hyper Text Markup Language merupakan salah satu format yang digunakan dalam pembuatan dokumen dan aplikasi yang berjalan di halaman $W e b$. Dokumen ini dikenal sebagai $W e b$ Page. Dokumen HTMLmerupakan dokumen yang disajikan pada Web Brower.

HTML (Hyper Text Markup Language) adalah bahasa pengkodean untuk menghasilkan dokumen-dokumen
Hypertext untuk digunakan di World Wide Web. HTML merupakan bahasa markup yang digunakan untuk pembuatan tampilan, layout atau tata letak suatu website.

6. XAMPP

Menurut Riyanto (2013:1), XAMPP merupakan paket PHP dan MySQL berbasis open souce, yang dapat digunakan sebagai tool pembantu pengembangan aplikasi berbasis PHP.

Fungsi XAMPP adalah sebagai server yang berdiri sendiri (localhost), yang terdiri atas program Apache HTTP Server, MySQL database, dan penerjemah bahasa yang ditulis dengan bahasa pemrograman PHP dan Perl. Nama XAMPP merupakan singkatan dari $\mathrm{X}$ (empat sistem operasi apapun), Apache, MySQL, PHP dan Perl. Program ini tersedia dalam GNU General Public License dan bebas, merupakan web server yang mudah digunakan yang dapat melayani tampilan halaman web yang dinamis..

7. Adobe Dreamweaver CS6

Menurut Menurut MADCOMS (2010:1), Dreamweaver merupakan Software aplikasi yang digunakan sebagai HTML, editor profesional untuk mendesain Web secara Visual. 
Adobe Dreamweaver merupakan aplikasi penyunting untuk halaman Web yang dikeluarkan oleh Adobe Systems yang sebelumnya dikenal dengan Macromedia Dreamweaver keluaran Macromedia. Adobe kembali mengeluarkan varian terbaru dari Dreamwevear yaitu Dreamwevear CS6.

\section{ANALISIS DAN PERANCANGAN SISTEM}

\section{A. Analisis}

Adapun teknik analisa yang digunakan penulis dalam menyelesaikan penelitian ini adalah dengan menggunakan System Development Life Cycle (SDLC). SDLC adalah tahapantahapan pekerjaan yang dilakukan oleh analis sistem dan programmer dalam membangun sistem informasi.

\section{B. Desain Sistem}

Berdasarkan tahapan pada pemodelan sistem yang penulis gunakan, maka penulis akan menjelaskan tentang Unifield Modelling Language (UML) dan database yang digunakan.

\section{Desain Proses}

Pada tahapan ini akan menguraikan dalam beberapa diagram yaitu use case diagram, activity diagram, dan class diagram. a. Use Case Diagram

Use case diagram menggambarkan terdapat dua actor admin dan user dimana use case ini merupakan suatu desain proses dari aplikasi ilmu biologi berbasis android. Use case diagram dapat dilihat pada gambar 1 berikut ini.

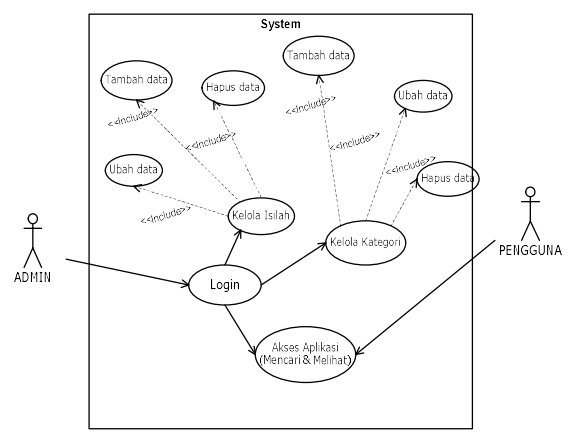

Gambar 1. Use Case Diagram

\section{b. Class Diagram}

Class diagram menggambarkan struktur dan deskripsi class, package dan objek beserta hubungan satu sama lain seperti containment, pewarisan, asosiasi, dan lain-lain. Berikut class diagram aplikasi kamus ilmu biologi berbasis android dapat dilihat pada gambar 2 .

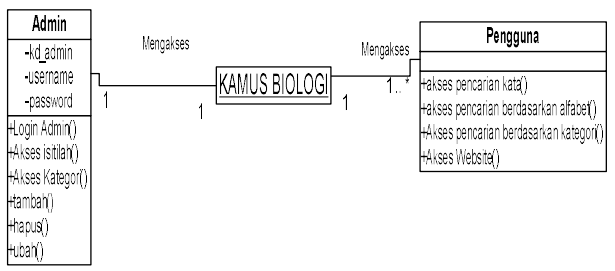

\section{Gambar 2. Class Diagram}

c. Pembuatan database

Sebelum membuat halaman web, terlebih dahulu dibuat databasenya agar 
pembuatan halaman dalam aplikasi dapat berjalan dengan baik.

Database dibuat terlebih dahulu karena saat membuat halaman aplikasi digunakan koneksi ke database. Dalam aplikasi terdapat satu buah database yaitu "kamus.sql".

d. Pembuatan tabel

Langkah selanjutnya adalah membuat tabel dalam database. Dalam database ini akan dibuat sebanyak sebelas buah tabel database sebagai tempat untuk meyimpan data profil, tabel-tabel tersebut antara lain sebagai berikut:

\section{1) Tabel Admin}

Tabel admin digunakan untuk meyimpan data admin yang mengolah semua data pada aplikasi ini, juga sebagai akses untuk login ke halaman admin .

Tabel 1. Struktur admin

\begin{tabular}{|l|l|}
\hline \multicolumn{1}{|c|}{ Field } & \multicolumn{1}{c|}{ Type data } \\
\hline kd_admin* & $\operatorname{Int}(5)$ \\
\hline Username & Varchar(30) \\
\hline Password & Varchar(50) \\
\hline
\end{tabular}

2) Tabel Data Istilah

Tabel istilah untuk meyimpan data isitlah kata dalam aplikasi kamus.

Tabel 2. Struktur Istilah

\begin{tabular}{l|l} 
Field & Type data
\end{tabular}

\begin{tabular}{|l|l|}
\hline Kd_istilah* & $\operatorname{Int}(10)$ \\
\hline $\begin{array}{l}\text { Kd_kategori } \\
* *\end{array}$ & $\operatorname{Int}(2)$ \\
\hline Kd_alphabet & Varchar(1) \\
\hline kata & Varchar(11) \\
\hline Arti & Text \\
\hline gambar & Varchar(50) \\
\hline
\end{tabular}

3) Tabel Kategori

Tabel kategori digunakan untuk meyimpan data kategori dalam halaman aplikasi.

Tabel 3. Struktur Kategori

\begin{tabular}{|c|l|}
\hline Field & \multicolumn{1}{|c|}{ Type data } \\
\hline Kd_kategori & Int(10) \\
\hline Nm_kategori & Varchar(20) \\
\hline
\end{tabular}

Sebelum membuat aplikasi terlebih dahulu dibuat beberapa folder yang akan digunakan untuk meyimpan file-file web nantinya. Adapun folder-folder tersebut adalah sebagai berikut:

1) Folder kamus

Tabel ini berisi file-file folder dan sub folder yang digunakan sebagai konten untuk membuat halaman dan sebagai konten. File-file tersebut antara lain admin, assets, connect, gaya, sebagai file untuk akses konten- konten yang terdapat halaman utama aplikasi.

2) Sub folder dbprofil

a) $\mathrm{Sub} \quad$ folder Admin 
index.php, kategori.php, menu.php, data_alphabet.php, data_kategori.php, f_istilah.php, f_kategori.php, dan lainlain yang kesemuanya digunakan untuk mengelola proses simpan, edit, hapus, data tabel yang ada pada database.

b) Sub folder assets

Sub folder assets berisi file untuk mengelola tampilan aplikasi agar lebih bagus.

c) Sub image

Di dalamnya terdapat file gambar yang digunakan dalam sistem.

\section{f. Desain Interface}

1) Halaman pengunjung

Halaman utama aplikasi merupakan halaman aplikasi yang tersedia dan diakses oleh pengunjung. Adapun tahapan ini akan dibuat file-file PHP untuk halaman utama. Dapat dilihat pada gambar 3. Halaman Pengunjung.

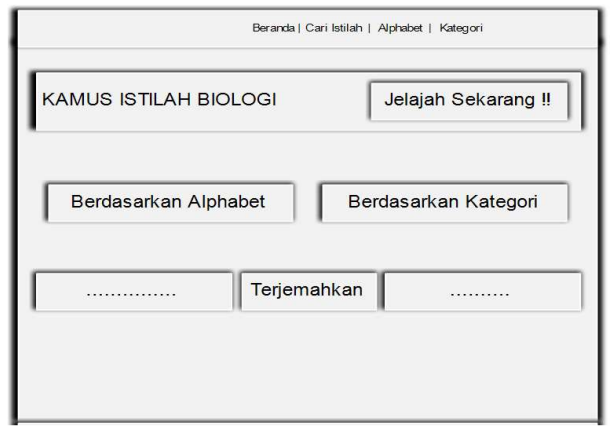

Gambar 3. Halaman Pengunjung

2) Halaman administrator

Merupakan halaman administrator yang hanya dapat diakses oleh admin untuk mengolah data dan informasi yang ada pada halaman website. Halaman ini dikhususkan untuk pengelola atau admin saja. Rancangan menu admin dapat dilihat pada gambar 4 .

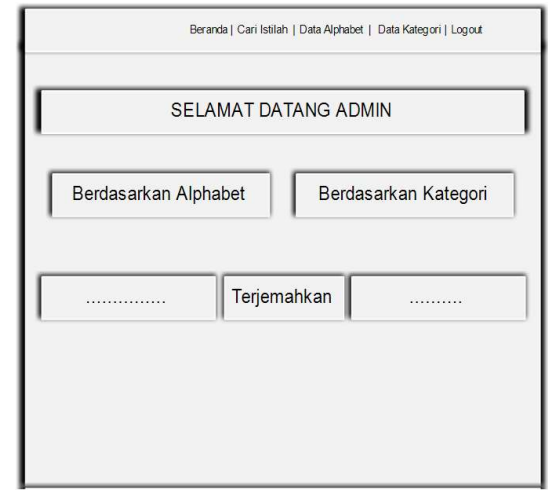

Gambar 4. Halaman Administrasi

\section{IMPLEMENTASI DAN \\ PEMBAHASAN}

Implementasi merupakan tahap pengembangan rancangan menjadi kode program dan menjalankan kode progam agar website dapat berjalan sesuai rancangan.

Dari proses implementasi maka terbentuklah sebuah aplikasi untuk memberikan informasi kepada masyarakat tentang profil Kecamatan Rungan, pembahasan secara garis besar dari hasil implementasinya adalah sebagai berikut:

1. Halaman Utama Pengunjung

Pada halaman utama pengunjung menampilkan menu, diantaranya adalah 
beranda, cari istilah, kategori, alphabet, dan login. Dapat dilihat pada gambar 5 .

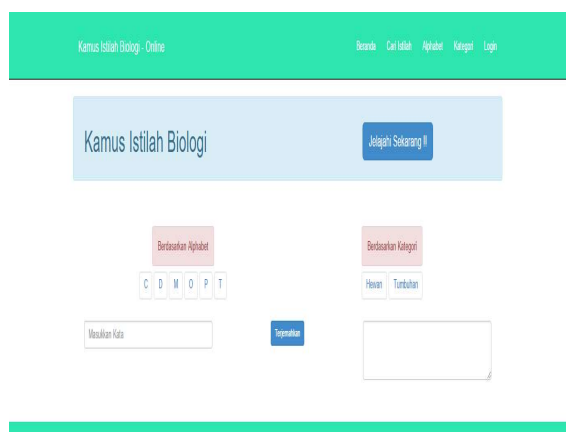

Gambar 5. Halaman Utama Pengunjung

2. Halaman Utama Admin

Halaman utama admin berisi beranda, dan menu untuk mengelola data istilah kata berdasarkan kategori dan alphabet, untuk menu terdapat fasilitas untuk mencari istilah, kategori, alphabet serta menu keluar. Berikut adalah gambaran halaman utama admin dapat dilihat pada gambar 6 .

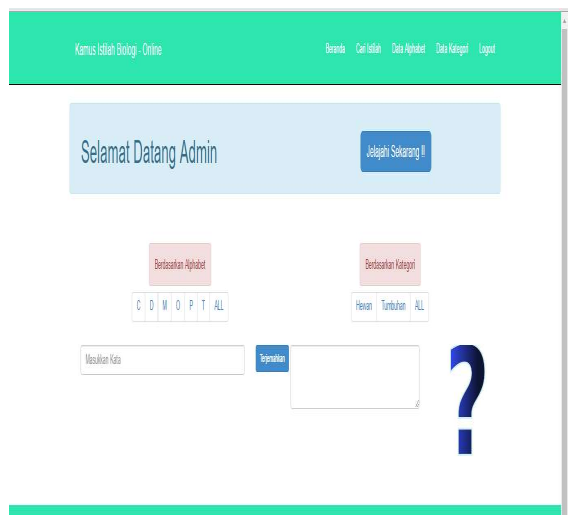

Gambar 6. Halaman Utama Admin

\section{PENUTUP}

\section{A. Kesimpulan}

Berdasarkan pemaparan pada analisa, implementasi dan pengujian dari aplikasi kamus yang dibangun maka penulis dapat menarik kesimpulan sebagai berikut:

1. Pada aplikasi kamus biologi telah berhasil dibuat dengan menggunakan bahasa pemrograman $p h p$ dan database yang digunakan berbasis Struktured Query Language (SQL) yaitu MySQL dengan nama kamus.sql dengan 3 (tiga) buah tabel.

2. Aplikasi kamus biologi ini diharapkan masyarakat dapat melihat atau mencari arti dari istilah kata yang berhubungan dengan biologi yang telah diupdate oleh admin.

\section{B. Saran}

Pengembangan aplikasi kamus ini kedepannya penulis memberikan beberapa saran yaitu sebagai berikut:

1. Penambahan fitur yang lebih kompleks atau tidak hanya satu displin ilmu tapi lebih kompleks seperti IPA dimana di dalamnya terdapat pilihan ilmu biologi dan fisika.

2. Pengembang dapat memperbaiki desain antar muka sehingga tampilan lebih baik dan menarik lagi. 
3. Jumlah suku kata yang lebih banyak sehingga bendahara katanya lebih kaya.

\section{DAFTAR PUSTAKA}

Aditya, N .A. 2011. Jago PHP \& $M y S Q L$, Dunia komputer, Bekasi.

Arief, M. R. 2011. Pemrograman Web Dinamis Menggunakan PHP dan Mysql, Andi, Yogyakarta.

Jogiyanto H. M . 2003. Analisis \& Desain Sistem Informasi : Pendekatan Terstruktur Teori dan Praktik Aplikasi Bisnis, Andi, Yogyakarta.

Murtiwiyati. 2013. Kupas Tuntas Web Responsif, Elex Media Komputindo, Jakarta.

Nugroho, Muhammad. 2003. Keaneka Ragaman Hayati. Pusaka Ilmu. Jakarta.

MADCOMS. 2010. Kupas Tuntas Adobe Dreamweaver CS6 dengan Pemrograman PHP \& MySQL, Andi, Yogyakarta.

Pelita Informatika Budi Darma Vol.5 No.3, Desember 2013, Implementasi Algoritma String Matching Pada Kamus IstilahIstilah Kedokteran Berbasis Android, Ihsan.

Perpustakan Nasional RI: Katalog Dalam Terbitan (KDT), 2009, Ensiklopedia Kebahasaan Indonesia. Angkasa, Bandung.
PESAT (Psikologi, Ekonomi, Sastra, Arsitektur dan Sipil), 18-19 Oktober 2011, Aplikasi Mobile Kamus Istilah Psikologi Berbasis Android 2.2, Parno, Dharmayanti, Nandang.

Riyanto. 2013. Membangun Mobile Web Store dengan CodeIgniter, MySQL \&jQuery Mobile, ANDI, Yogyakarta.

Safaat H, Nazruddin. 2011. Pemrograman Aplikasi Mobile Smartphone dan Tablet PC Berbasis Android. Informatika Bandung, Bandung. 